\title{
BMJ Open Household cooking fuel type and childhood anaemia in sub-Saharan Africa: analysis of cross-sectional surveys of 123, 186 children from 29 countries
}

\author{
Iddrisu Amadu (D) , , ${ }^{1,2}$ Abdul-Aziz Seidu (D) ,3,4,5 Abdul-Rahaman Afitiri, ${ }^{6}$ \\ Bright Opoku Ahinkorah (D) ,' Sanni Yaya ${ }^{8,9}$
}

To cite: Amadu I, Seidu A-A, Afitiri A-R, et al. Household cooking fuel type and childhood anaemia in sub-Saharan Africa: analysis of cross-sectional surveys of 123,186 children from 29 countries. BMJ Open 2021;11:e048724. doi:10.1136/ bmjopen-2021-048724

- Prepublication history for this paper is available online. To view these files, please visit the journal online (http://dx.doi. org/10.1136/bmjopen-2021048724).

Received 06 January 2021 Accepted 30 June 2021

\section{Deck for updates}

(c) Author(s) (or their employer(s)) 2021. Re-use permitted under CC BY-NC. No commercial re-use. See rights and permissions. Published by BMJ.

For numbered affiliations see end of article.

Correspondence to Dr Abdul-Aziz Seidu; abdul-aziz.seidu@stu.ucc. edu.gh

\section{ABSTRACT}

Objective This study sought to investigate the joint effect of household cooking fuel type and urbanicity (rural-urban residency) on anaemia among children under the age of five in sub-Saharan Africa.

Design We analysed cross-sectional data of 123,186 children under the age of five from 29 sub-Saharan African countries gathered between 2010 and 2019 by the Demographic and Health Survey programme. Bivariate $\left(\chi^{2}\right.$ test of independence) and multilevel logistic regression were used to examine the effect of urbanicity-household cooking fuel type on childhood anaemia. Results were reported as adjusted odds ratios (aORs) with $95 \% \mathrm{Cls}$ at $p<0.05$.

Outcome measures Anaemia status of children. Results More than half $(64 \%)$ of children had anaemia. The percentage of children who suffered from anaemia was high in those born to mothers in Western Africa (75\%) and low among those born in Southern Africa (54\%). Children from rural households that depend on unclean cooking fuels (aOR=1.120; $95 \% \mathrm{Cl} 1.033$ to 1.214$)$ and rural households that depend on clean cooking fuels (a0R=1.256; 95\% $\mathrm{Cl} 1.080$ to 1.460) were more likely to be anaemic as compared with children from urban households using clean cooking fuel. Child's age, sex of child, birth order, perceived birth size, age of mother, body mass index of mother, education, marital status, employment status, antenatal care, wealth quintile, household size, access to electricity, type of toilet facility, source of drinking water and geographic region had significant associations with childhood anaemia status. Conclusions Our study has established a joint effect of type of household cooking fuel and urbanicity on anaemia among children under the age of five in sub-Saharan Africa. It is therefore critical to promote the usage of clean cooking fuels among households and women in rural areas. These should be done taking into consideration the significant child, maternal, household, and contextual factors identified in this study.

\section{INTRODUCTION}

In low/middle-income countries (LMICs), anaemia remains a major public health

\section{Strengths and limitations of this study}

- The major strength of this study is the use of recent nationally representative surveys, with relatively large sample sizes. This makes the findings generalisable to all under-five children in the countries we included in our study.

- Also, we employed rigorous statistical modelling to assess the effect of urbanicity-type of cooking fuel on childhood anaemia while controlling for theoretical and practical confounders.

- The study, however, is limited by the cross-sectional nature of the design employed for the data collection. Due to this, it is impossible to detect temporality of sequence.

- Considering that several proximal, intermediate and distal factors could moderate the effects of household cooking fuel type and urbanicity on child anaemia, we acknowledge that those considered in this study are not exhaustive. Based on data availability, practical relevance and parsimony, the variables included in this study were chosen.

problem which causes childhood mortality and morbidity. ${ }^{1}$ Anaemia is a condition in which the haemoglobin $(\mathrm{Hb})$ level is lower than the body's required amount for physiological activities. ${ }^{2}$ According to $\mathrm{WHO},{ }^{3}$ about 273.2 million children suffer from anaemia globally with a general prevalence of $42.6 \%$. However, its effects are disproportionate across regions, with sub-Saharan Africa (SSA) being one of the most affected with a startling prevalence rate of $62.3 \%{ }^{4}$

Anaemia is a major contributor to some of the serious adverse health conditions in children and affects their cognitive, behavioural and physical development. ${ }^{35-7}$ The notable causes of anaemia in children are multifactorial and include deficiency of iron, and other micronutrients such as folate, vitamin B12 
and vitamin A; malaria, HIV and chronic diseases such as sickle cell disease. ${ }^{8}$

Apart from these causes, a major environmental cause of anaemia is indoor air pollution as a result of biomass fuel use in cooking in households. ${ }^{9}$ Household biomass fuel is a global air pollution issue that harms human health, the climate and the environment. About 3 billion people use biomass fuels such as plant residues, animal dung, wood and charcoal for daily domestic use. ${ }^{10}$ Inefficient combustion of these fuels could release harmful gases such as sulphur dioxide $\left(\mathrm{SO}_{2}\right)$, carbon monoxide $(\mathrm{CO})$, nitrogen dioxide $\left(\mathrm{NO}_{2}\right)$, and particulate matter $(\mathrm{PM}) .{ }^{11}{ }^{12}$ According to $\mathrm{WHO},{ }^{12}$ households that use biomass fuels are often exposed to peak indoor particulate matter $\left(\mathrm{PM}_{10}\right)$ levels greater than the air quality guidelines. The mechanism by which biomass fuels use could contribute to childhood anaemia are unknown. However, it has been postulated by Accinelli $e t a l^{14}$ that biomass fuel exposure causes lung inflammation with elevated levels of interleukin 6 (IL-6), which produces in the liver hepcidin, a negative regulator of iron stores. However, studies have shown that biomass fuel expels high carbon monoxide levels which bind with $\mathrm{Hb}$, form carboxyhaemoglobin and reduce the level of $\mathrm{Hb}$ in the blood, which could lead to functional anaemia, with an adequate $\mathrm{Hb}$ level. For instance, studies in India ${ }^{9}$ and Swaziland ${ }^{11}$ found the prevalence of anaemia to be significantly high among children in households that rely on biomass fuels for cooking.

Apart from anaemia, evidence of other adverse health outcomes spanning respiratory illnesses, cancer and eye problems from indoor air pollution due to inefficient burning of biomass fuels for cooking in poorly ventilated settings exist. ${ }^{15-17}$ A majority of the burden is suffered by women who by custom are responsible for cooking and other household chores, and their children, especially, those below the age of $5 .{ }^{1718}$ The prevalence of the burden is relatively low in urban areas where clean fuels like liquefied petroleum gas or natural gas and electricity are typically used. However, most rural residents mainly depend on biomass fuels. ${ }^{19}$ These fuels include among others wood, animal dung, twigs, and dry leaves, and crop residues such as straw and rice husks. ${ }^{20}$ The high burden of adverse health outcomes among rural residents is that most of them often depend on unclean cooking fuels. $^{162122}$

The associations between household biomass fuel use in cooking and important health variables of women and children such as adverse pregnancy outcomes (low birth weight, stillbirth) ${ }^{1523}$ women health (body mass index (BMI), anaemia),${ }^{15}{ }^{24}$ and the health of children under 5 years of age (child weight, child anaemia) ${ }^{1623}$ have been examined. Few studies have examined the association between household biomass fuel use, a notable source of indoor air pollution in LMICs and childhood anaemia in SSA. Further, critical to our understanding but absent in such subregional analysis by studies is the joint impact of household biomass fuel use and urbanicity on child anaemia in SSA. This study, therefore, investigated the joint effect of household biomass fuel use for cooking and urbanicity on anaemia among children under the age of five in SSA.

\section{METHODS}

\section{Data and sampling}

Nationally representative data from the Demographic and Health Surveys (DHS) Program for 29 countries in SSA from 2010 to 2019 were acquired for analysis in this study. The DHS Program provides large secondary data gathered from surveys using probability sampling methods, following standard protocols that are internationally accepted. Different sets of questionnaires designed and pretested to ensure reliability and amenability for comparison of data gathered on various spatial and temporal scales are used in the survey. Some questionnaires the Program uses include the 'children's questionnaire' 'mother's questionnaire', 'men's questionnaire' and 'household questionnaire'. These questionnaires cover a broad range of variables cutting across demographics and anthropometrics, water and sanitation, health, wealth, nutrition among others. The Program recruits and trains field officers to collect accurate data and measurement of weight, height, anaemia using recommended guidelines and instruments. Data on other important variables such as household cooking fuel, urbanicity, wealth, water and sanitation are taken at the household level. The dataset used in this study are: Children's Data-Children's Recode, and Household Data-Household Recode (variable names: caseid; v000; v001 v007; v013; v102; v113; v116; v136; v149; v151; v152; v190; bord; b4; b8; m19; hw2; v457; v005; hhid; hv001, hv000; hv226).

\section{Study countries}

A sample of 123,182 was drawn from 29 countries (figure 1) accros the five geographic regions-Western, Eastern, Central and Southern Africa in SSA. For a country to be selected, it must meet the following criteria: should be found in SSA based on the United Nations regional groupings; it must have a DHS dataset with standardised questions and observations on anaemia level of children under 5 years as well as household cooking fuel type, urbanicity, source of drinking water and type of toilet facility. Where multiple datasets exist for a country, the most recent dataset is used.

\section{Definition of important variables}

The dataset provided information on household cooking fuel type, source of drinking water and toilet facility type at the household level. The observations for household cooking fuel were classified into 'clean' and 'unclean' (polluting fuels) following the criteria used in previous studies $^{25} 26$ (see table 1). The weight of the child at birth named as 'birth weight' was categorised as 'underweight' $(<2.5 \mathrm{~kg})$ and 'normal' $(\geq 2.5 \mathrm{~kg})$ (see Yaya et $\left.^{2 l^{27}}\right)$. Also, the 


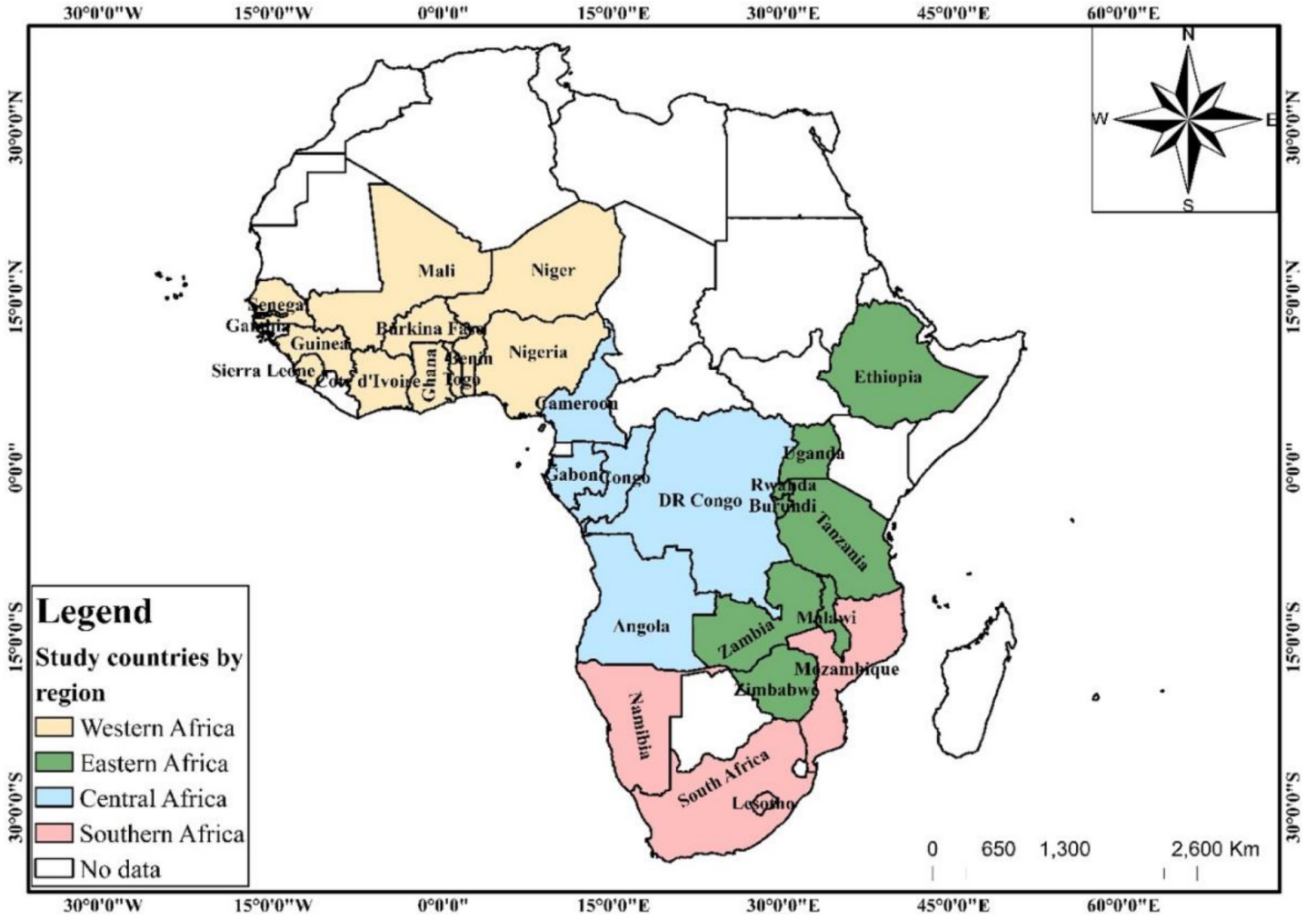

Figure 1 Map of study countries.

observations for the household source of drinking water and type of toilet facility were classified into 'improved' and 'unimproved' using the revised definitions by the WHO/UNICEF Joint Monitoring Programme report. ${ }^{28}$ The improved and unimproved drinking water sources and toilet facilities categorisation as described by Armah et $a t^{29}$ are summarised in Table 2.

\section{Measures}

Outcome variable

Anaemia status of children is the outcome variable considered in this study. According to DHS, the anaemia status of living children within the age bracket $0-4$ years before the survey night was taken. It has its responses classified into four categories according to the WHO recommendation as (i) 'not anaemic' for children with $\mathrm{Hb}$ count $(\mathrm{g} / \mathrm{L}$ ) measuring above $110 \mathrm{~g} / \mathrm{L}$; (ii) 'mild anaemia' for $\mathrm{Hb}$ count of 100-109g/L; (iii) 'moderate anaemia' for $\mathrm{Hb}$ count between 70 and $99 \mathrm{~g} / \mathrm{L}$ and (iv) 'severe anaemia' for $\mathrm{Hb}$ count less than $70 \mathrm{~g} / \mathrm{L}$. Children with no observations for anaemia count (not tested) and those whose mothers were not listed in the household questionnaire were excluded. Observations under mild, moderate and severe were combined and recoded as ' 1 ' for 'anaemic' and observations under not anaemic was recoded as ' 0 ' 'normal' (see Chandran and Kirby ${ }^{30}$ ). This produced the dichotomous outcome variable 'anaemia status'.

\section{Main predictor variable}

The predictor chosen for this study is a composite variable derived from household cooking fuel type and urbanicity. The selection of the predictor variable was based on parsimony, literature review, theoretical relevance as well as practical significance. Household cooking fuel type and urbanicity both had two categories since the former was classified as 'clean' and 'unclean' and the

Table 1 Classification of the source of drinking water and toilet facilities under the WHO/UNICEF Joint Monitoring Programme and cooking fuel

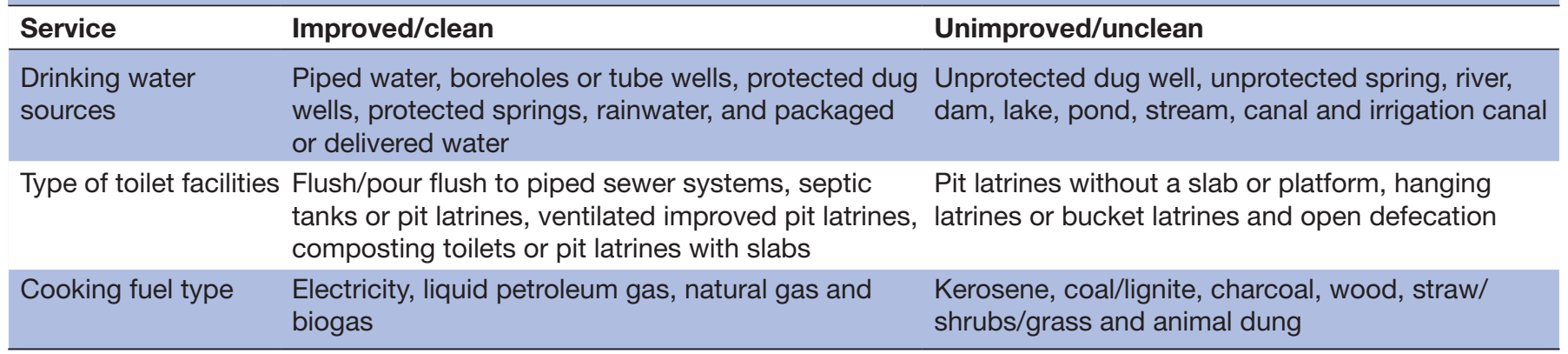




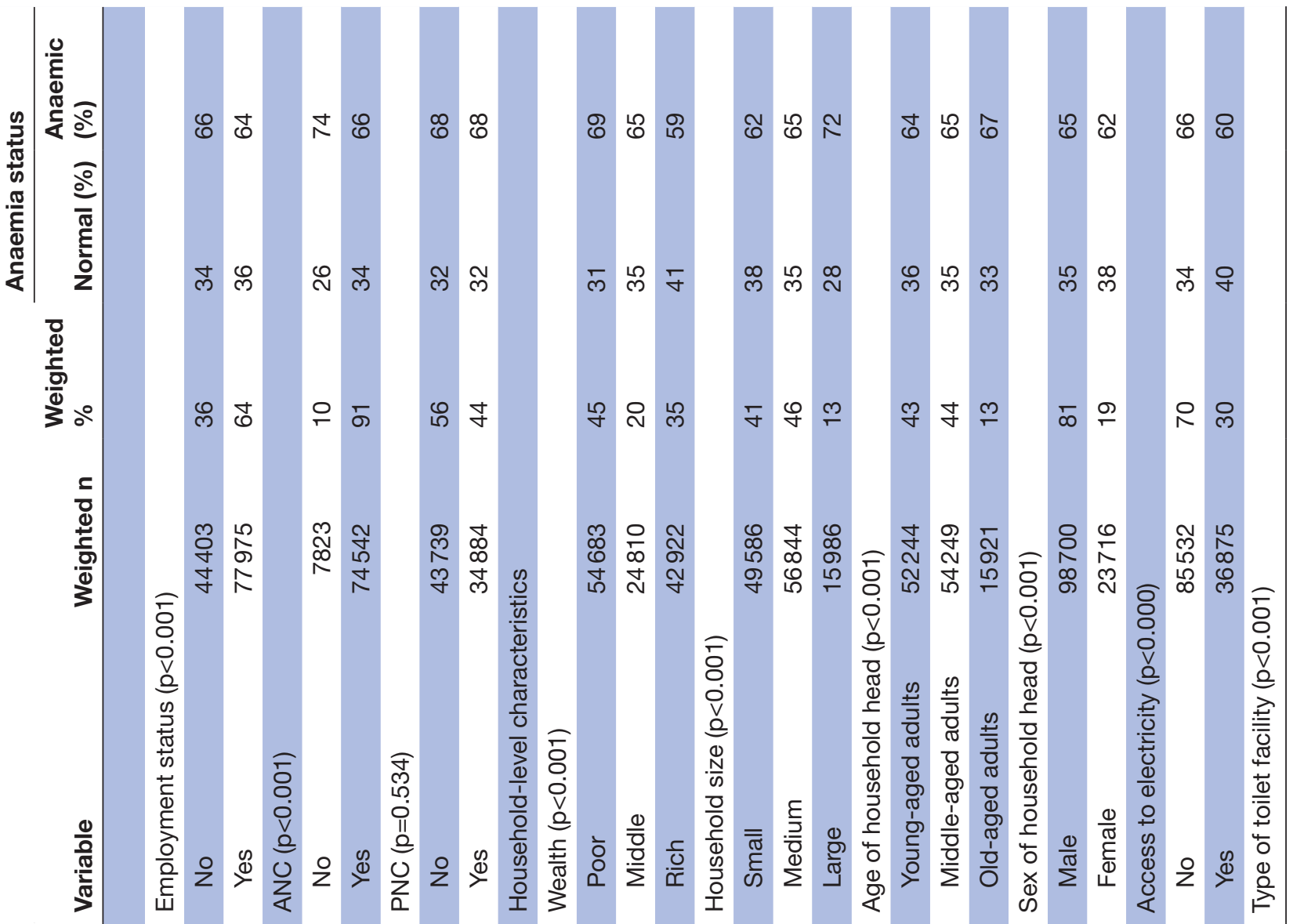

营
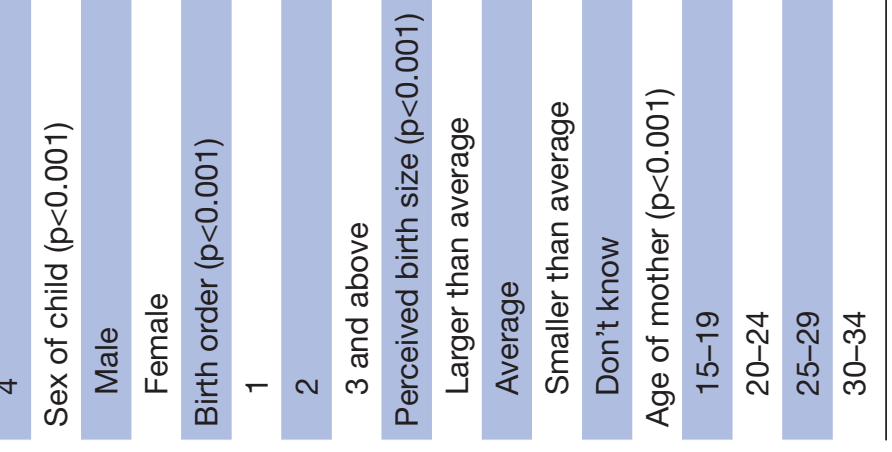


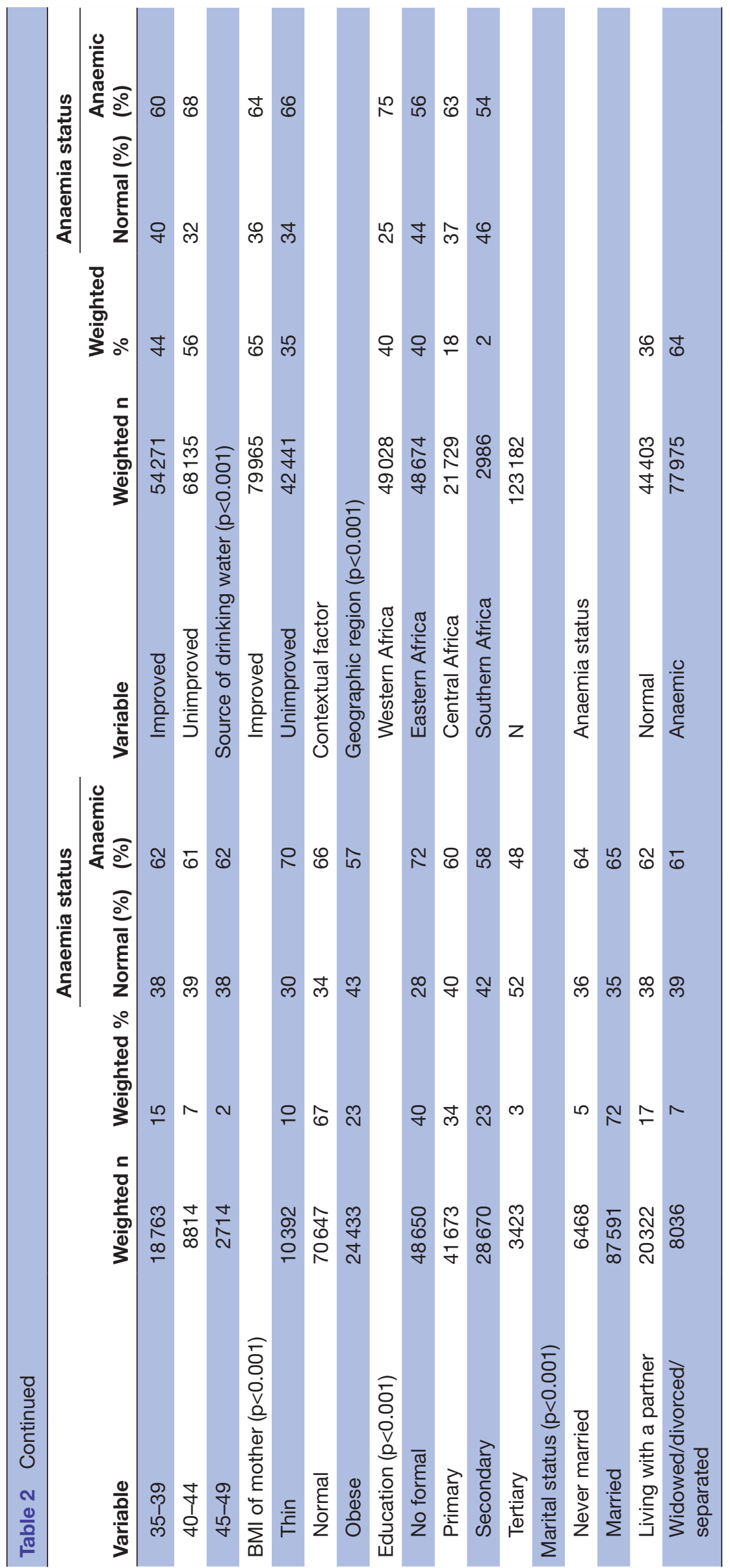

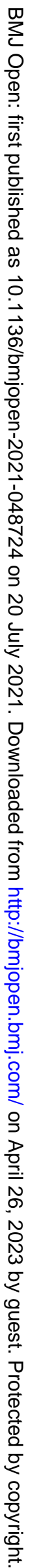


latter measured as 'rural' and 'urban' per the DHS. This, therefore, gave four mutually exclusive groups: uncleanurban (households relying on 'unclean' cooking fuel and found in urban areas); unclean-rural (households relying on 'unclean' cooking fuel and found in rural areas); clean-urban (households using 'clean' cooking fuels and found in urban areas) and clean-rural (households using 'clean' cooking fuels and found in rural areas). This variable combination technique has been widely applied in previous studies. ${ }^{29} 31$ Out of the four responses, 'clean-urban' was chosen as the reference category in the models. Even though urban residents are commonly exposed to outdoor pollution, emissions from household cooking fuels (indoor pollution) is a major problem to rural residents owing to their relatively high dependence on unclean cooking fuels ${ }^{32} 33$ This formed the basis for the choice of reference category.

\section{Covariates}

There is a plethora of evidence on the independent associations between the type of household cooking fuel and urbanicity with childhood anaemia. ${ }^{142233-35}$ Even though the UNICEF categorisation of the factors that influence the association between household cooking fuel and child anaemia-proximal, immediate and distal factors serves as a useful framework, for parsimony, practical and theoretical considerations, we categorise independent variables drawn from literature under 'individual-level characteristics', 'household characteristics' and 'contextual factors' (see Nambiema et $a l^{4}$ and Amadu et $a l^{36}$ ). The individual-level characteristics considered in this study are child age in years $(0,1,2,3$ and 4$)$; sex of child (male, female); birth order (1, 2, 3 and above); perceived birth size (larger than average, average, smaller than average, don't know); birth weight (underweight, normal); age of the mother (15-19, 20-24, 25-29, 30-34, 35-39, 40-44, 45-49); body mass index (BMI) of the mother (thin, normal and obese); education (no formal, primary, secondary and tertiary); marital status (never married, married, living with a partner, widowed/divorced/separated); employment status (no, yes); number of antenatal care (ANC) by mother (no, yes); and number of postnatal care (PNC) by mother (no, yes).

The relevant household-level factors included in this study are wealth status (poor, middle, rich); household size ('small' for those with 1-5 members; 'medium' 5-10 members and 'large' for more than 10 members); age of household head ('young-aged adults' for those age below 35; 'middle-aged adults' for those between 35 and 64 years and 'old-aged adults' for those 65 years and above); sex of household head (male, female); access to electricity (no, yes); type of toilet facility (improved, unimproved); and source of drinking water (improved, unimproved).

Finally, we adjusted for the effect of the contextual factor 'geographic region' (Western Africa, Eastern Africa, Central Africa, Southern Africa). Variables in this category of factors relate to the attributes of respondent's neighbourhood, and opportunities and services that are space-bound. ${ }^{37} 38$

\section{Data analyses}

The Stata V.14.0 MP (Stata Corporation) software was used for the analysis of data. The data were first declared as a survey dataset to prevent potential errors that could arise from the complex survey design using the 'svyset' command with the cluster, weighting and strata variables. To understand the distribution of childhood anaemia and the influence of predictive factors on anaemia, descriptive analysis was performed. Using ArcGIS V.10.6, the data were integrated with ESRI Shapefiles to construct a map of the study countries showing the distribution of childhood anaemia. We then determined the associations between the anaemia status of children under five and the relevant predictors using the $\chi^{2}$ test of independence. These relationships were further examined by implementing five multilevel logistic regression models. The first model (model 0) with no independent variable indicated the variance in child anaemia as a result of clustering of the primary sampling units. In model I, only the main predictor variable (urbanicity-type of cooking fuel) was included. Model II adjusted for the individuallevel characteristics. The effects of both individual-level and the relevant household-level factors were adjusted in model III. Model IV controlled the individual-level and household-level characteristics, and the contextuallevel factors. The Akaike's Information Criterion was the model comparison metric estimated. Results were presented using adjusted ORs (aORs) at $\mathrm{p}<0.05$ and $95 \%$ CIs.

\section{Patient and public involvement}

Patients and the public were not involved in the design and conduct of this research.

\section{RESULTS}

\section{Descriptive analysis}

The study included 123, 182 children under the age of 5 years from 29 countries in SSA. The percentage of children who suffered anaemia was $64 \%$. The prevalence of anaemia was high in children born to mothers in Western Africa $(75 \%)$ and low among those born in Southern Africa (54\%) (figure 2). A majority (68\%) of the children included in the survey were in rural households that used unclean cooking fuels, $24 \%$ were aged $1,51 \%$ were male, $48 \%$ were of second birth order and $50 \%$ were of average size at birth. Most of the children included in the survey were born to mothers aged 25-29 (27\%), mothers with normal BMI $(67 \%)$, mothers with no formal education $(40 \%)$, married mothers $(72 \%)$, employed mothers (64\%), mothers who attended ANC (91\%) and mothers who did not attend PNC (56\%). A majority of the children belonged to poor households (45\%), households with medium size $(46 \%)$, households with middle-aged adults heads $(44 \%)$, households with male heads $(81 \%)$, 


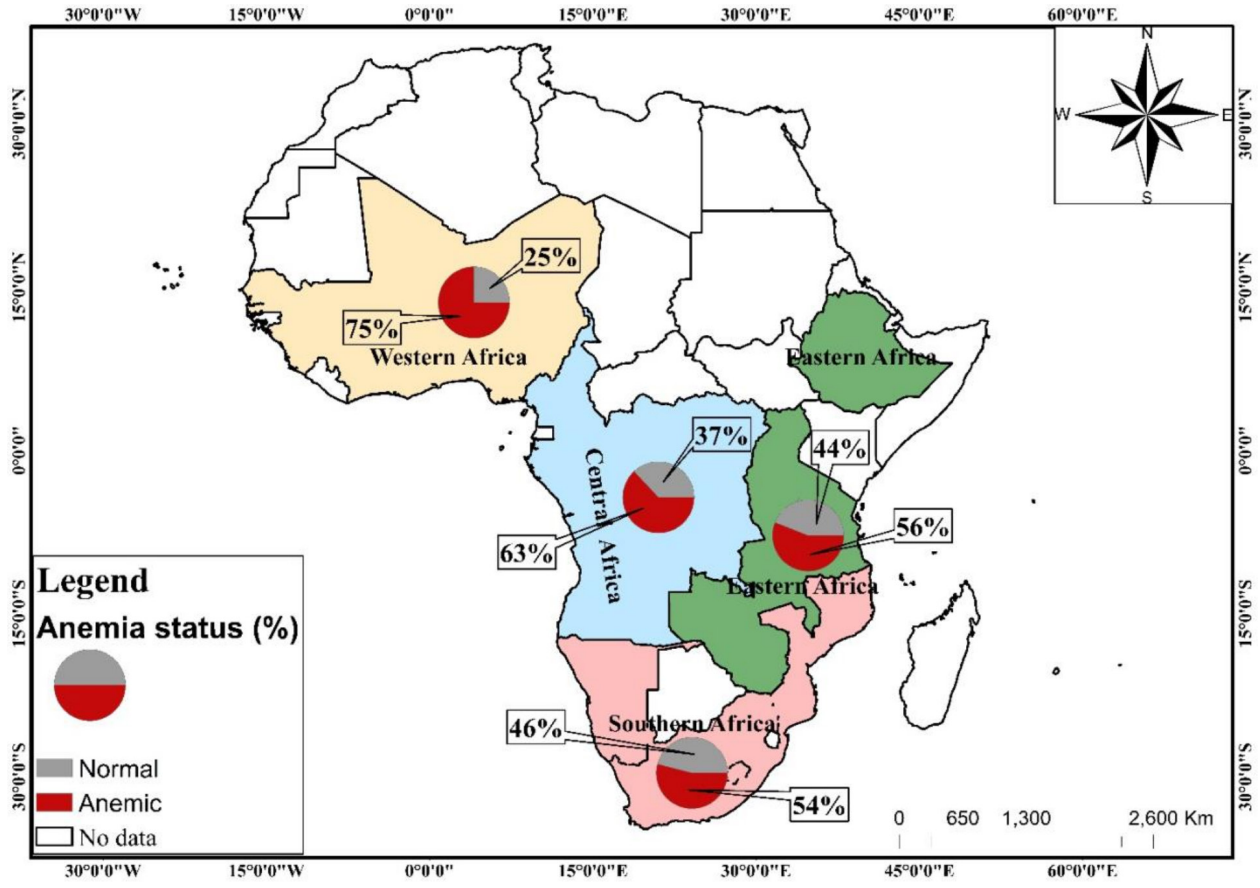

Figure 2 Map of study countries showing the distribution of children under age 5 years anaemia status.

households with no access to electricity (70\%), households with an unimproved toilet facility $(56 \%)$ and households with improved drinking water $(65 \%)$. Most of the children included in the study were in Western Africa $(40 \%)$ and Eastern Africa (40\%). Significant differences in the distribution of anaemia status were found in all the in-predictor variables, except PNC attendance (table 2).

\section{Multivariate analysis}

Table 3 shows the multilevel logistic regression results on the joint effect of urbanicity and type of household cooking fuel on childhood anaemia in SSA. In model IV, the final model that controlled for all the variables including georaphic region, it was found that children from rural households that depend on unclean cooking fuels ( $\mathrm{aOR}=1.120 ; 95 \%$ CI 1.033 to 1.214 ) and rural households that depend on clean cooking fuels $(\mathrm{aOR}=1.256$; $95 \%$ CI 1.080 to 1.460 ) were more likely to be anaemic as compared with children from urban households using clean cooking fuel.

The odds of childhood anaemia decreased with the age of the child. It was found that children aged 4 had the lowest odds ( $\mathrm{aOR}=0.264 ; 95 \%$ CI 0.247 to 0.283 ) of suffering from anaemia compared with those less than 1 year $(0)$. Female children were less likely to be anaemic compared with male children $(\mathrm{aOR}=0.857 ; 95 \%$ CI 0.829 to 0.887 ). Children with three or more birth orders were more likely to be anaemic compared with first birth order children (aOR=1.269; 95\% CI 1.179 to 1.367 ). Children with smaller than average birth size were more likely to be anaemic compared with those who were larger than average (aOR=1.075; 95\% CI 1.020 to 1.132$)$.

The odds of anaemia in children under five were lower among those born to mothers aged 45-49 compared with those aged $15-19$ (aOR=0.559; 95\% CI 0.484 to 0.645$)$. Children born to mothers with normal BMI were less likely to be anaemic compared with born to children with thin mothers $(\mathrm{aOR}=0.923 ; 95 \%$ CI 0.870 to 0.979$)$. Children born to mothers with tertiary educational level were less likely to be anaemic compared with those whose mothers had no formal education ( $\mathrm{aOR}=0.534 ; 95 \%$ CI 0.480 to $0.595)$. Children born to widowed/divorced/separated mothers were more likely to be anaemic compared with those who were never married $(\mathrm{aOR}=1.102 ; 95 \%$ CI 1.003 to 1.211). Children born to mothers who attended ANC were less likely to be anaemic compared with those who never attended ANC (aOR=0.931; 95\% CI 0.874 to 0.991$)$.

The odds of anaemia in children under five was lower among children born to mothers in rich households compared with those born to mothers in poor households (aOR $=0.888 ; 95 \%$ CI 0.844 to 0.935$)$. Children born to mothers in larger households were more likely to be anaemic compared with those born to mothers in small households (aOR=1.240; 95\% CI 1.163 to 1.321). Children born to mothers in households with access to electricity were less likely to be anaemic compared with those born to mothers in household without access to electricity (aOR $=0.896 ; 95 \%$ CI 0.853 to 0.941$)$. Children born to mothers who lived in households with improved source of drinking water were less likely to be anaemic compared with those born to mothers who lived in households with unimproved source of drinking water $(\mathrm{aOR}=1.046 ; 95 \%$ CI 1.008 to 1.086). Compared with children born to mothers who live in Western Africa, those born to mothers who live in Southern Africa were less likely to be anaemic ( $\mathrm{aOR}=0.497 ; 95 \%$ CI 0.451 to 0.548 ) (see table 3). 


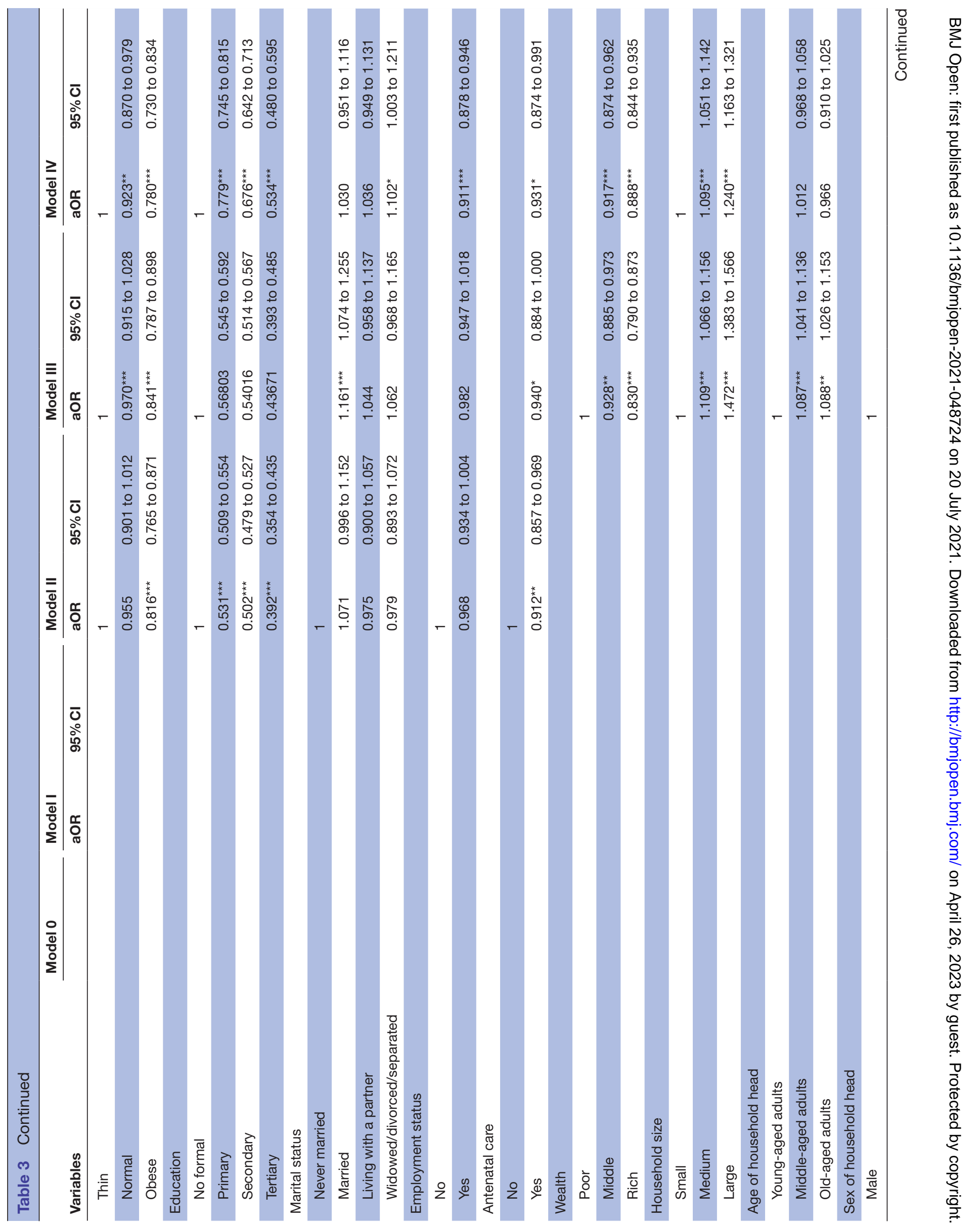




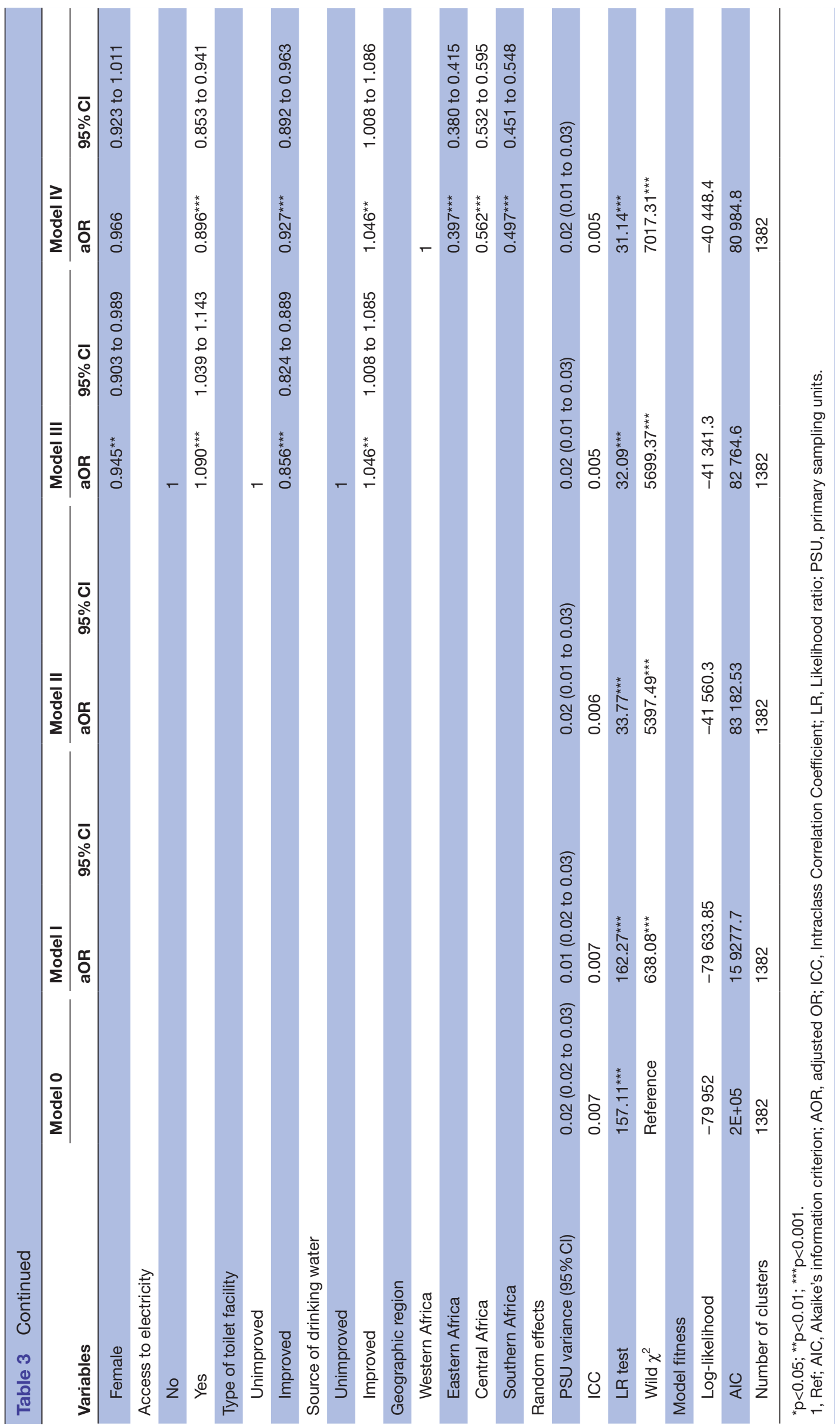

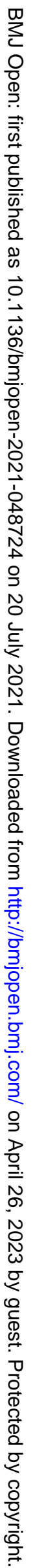




\section{DISCUSSION}

In this current study, our principal aim was to investigate the joint effect of household cooking fuel use and urbanicity on anaemia among children under the age of five in SSA. The study showed that children from rural households that depended on unclean cooking fuels were more likely to be anaemic compared with children from urban households using clean cooking fuel. This is in line with previous studies in various parts of the world such as Timor-Leste ${ }^{21}$ and India. ${ }^{1622}$ Although this study was crosssectional and could not claim causality, some studies ${ }^{16}$ have explained that exposure to unclean cooking fuels may lead to systemic inflammation which is regarded as a popular cause of anaemia, mediated by inflammatory cytokines such as tumour necrosis factor-alpha, IL-1, IL-6 and interferon- $\gamma .{ }^{169}$ The pathways by which these causes anaemia is that IL-6 increases with alveolus inflammation related to biomass pollution and hepcidin goes down, that stops the movement of $\mathrm{Fe}$, causing anaemia by inflammation. ${ }^{16}{ }^{39}$ Apart from the key independent variable, we controlled for other key factors associated with anaemia among children under five which are worth discussing in light of previous evidence.

We found that the birth weight of the child had a statistically significant association with anaemia. Specifically, children with normal weight had lower odds of being anaemic compared with underweight children. This aligns with previous studies in Ethiopia ${ }^{40}$ and Brazil. ${ }^{41}$ Some previous studies espoused that there is a direct link between food consumption and anaemia. Due to this, in a household where there is no food security, it can affect the nutritional status of children, which could contribute to anaemia. ${ }^{42}{ }^{43}$ Relatedly, we found that children in large households had higher odds of suffering from anaemia compared with those in a small household. This finding confirms a previous study in Ethiopia. ${ }^{44}$ Insufficient consumption of appropriate quantity of nutrients due to the high numbers in the households could possibly account for this observation as explained by Asresie $e t a{ }^{44}$

The study also established that the socioeconomic status (education and wealth) of women had a statistically significant association with childhood anaemia. Specifically, it was found that children whose mothers are in the rich wealth status, as well as those with tertiary level of education, have lower odds of being anaemic. This corroborates several previous studies in SSA and other countries such as Brazil,${ }^{45}$ Switzerland, ${ }^{46}$ Myanmar (Burma) ${ }^{47}$ and India. ${ }^{48}$ There are three pathways to the explanation of this finding. First, on the supply side, children from households with high-socio economic status can buy nutritious foods for their children, unlike the poor ones who might not be able to afford three square meals a day. In other words, the poor might lack the resources to purchase nutritious foods for their children. Second, evidence also suggests that mothers in poor households are also anaemic and the probability of their children also being anaemic is high. Third, in terms of education, mothers who are highly educated can translate the health education they receive during child welfare clinics into practice. Besides, those who are highly educated can recognise danger signs related to childhood illnesses that warrant emergency care. ${ }^{44} 49$

Another major finding in our study was that the odds of suffering from anaemia decreased with the age of the child. This finding is supported by other studies conducted in Ethiopia, ${ }^{40} 4250{ }^{51}$ Ghana $^{52}$ and Uganda. ${ }^{53}$ This observation is expected due to the fact that children have their least $\mathrm{Hb}$ value at 6 months and they continue increasing their values as they age.$^{54}$ We also observed a statistically significant association between maternal age and child's anaemia. Specifically, children whose mothers are aged 45-49 and those aged 30-34 had the lowest odds of being anaemic. This is consistent with previous studies in Ethiopia. ${ }^{44}$ It is possible that as mothers advance in age, they gain experiences with childcare and also, they are more likely to be exposed to education on appropriate practices on childhood nutrition compared with those who are adolescents. In line with a previous study, ${ }^{55}$ we also found that children in female-headed households, middle-aged adults, old age adults were more likely to be anaemic compared with those in male-headed households; and households headed by young adults. Surprisingly, our study showed that children in households with an improved source of drinking water had higher odds of being anaemic. This is contrary to other empirical studies in Bangladesh, ${ }^{56}$ India, ${ }^{22}$ Benin and Mali. ${ }^{57}$ Longitudinal case-control studies coupled with qualitative evidence are needed to unravel this counter-intuitive finding.

It is worthy to discuss the methodological limitations inherent in this study. First, although we controlled for several confounders, we could only control for those that were in the datasets. Second, various contextual issues could possibly explain the results we obtained from this study, nonetheless, we used multi-level analysis to account for the contextual variations. The study is also limited by the cross-sectional nature of the design employed for the data collection. Due to this, it is impossible to detect the temporality of sequence. ${ }^{58}$ There is also the possibility of error in measurement of the $\mathrm{Hb}$ levels, however, this is likely to be minimal since DHS uses standardised instruments across surveys and also uses experienced and welltrained data collectors. We did not also control for the dietary pattern and nutritional intake because the data are available for only children aged 6-23 months. In addition, we did not control for child's fever, diarrhoea and acute respiratory infection with anaemia since there are variations in the context, year and season of data collection across the surveys. ${ }^{585}$

\section{CONCLUSION}

Our study found a joint effect of household cooking fuel and urbanicity on anaemia among children under the age of five in SSA. Apart from this, we also found that birth weight of the child, age of the child, maternal age, sex of household head, age of household head, maternal 
education, wealth status, size of household, type of source of drinking water and country of residence are associated with childhood anaemia. The following recommendations are therefore made for policy and practice. First, it is critical to promote clean fuel usage among households and women in rural areas. This could be done by governments in various countries by enhancing access and subsidising the cost of natural and or, liquified petroleum gas and cylinders. It is, therefore, imperative to also improve road networks which can easily lead to accessible markets. Second, it is also important to advocate for improvement in female education which could lead to an improvement in the socioeconomic status of women. Third, there is the need for the installation of improved biomass stoves. Also, maternal education by community health nurses on the risk factors of anaemia is also strongly suggested. Stakeholders that seek to improve maternal and child health could also consider these associated factors.

\section{Author affiliations}

${ }^{1}$ Department of Fisheries and Aquatic Sciences, University of Cape Coast, Cape Coast, Ghana

${ }^{2}$ Africa Centre of Excellence in Coastal Resilience, University of Cape Coast, Cape Coast, Ghana

${ }^{3}$ Department of Population and Health, University of Cape Coast, Cape Coast, Ghana ${ }^{4}$ College of Public Health, Medical and Veterinary Services, James Cook University, Townsville, Queensland, Australia

${ }^{5}$ Department of Estate Management, Takoradi Technical University, Takoradi, Ghana ${ }^{6}$ Department of Environmental Science, University of Cape Coast, Cape Coast, Ghana

${ }^{7}$ University of Technology Sydney, Sydney, New South Wales, Australia

${ }^{8}$ School of International Development and Global Studies, University of Ottawa, Ottawa, Ontario, Canada

${ }^{9}$ The George Institute for Global Health, Imperial College London, London, UK

Acknowledgements We acknowledge the Demographic Health Surveys for providing us with the data upon which the findings of this study were based. Special thanks to Mr Eric Duku for his support in the spatial representation of child anaemia.

Contributors IA conceptualised and designed the study. IA and A-RA performed the analysis. IA, A-AS, A-RA, BOA and SY drafted the initial draft. AS, AA, BOA and SY provided technical support and critically reviewed the manuscript for its intellectual content. SY had the final responsibility to submit for publication. All authors read and amended drafts of the paper and approved the final version.

Funding The authors have not declared a specific grant for this research from any funding agency in the public, commercial or not-for-profit sectors.

Disclaimer Ethics approval was not required for this study since the data are secondary and are available in the public domain. More details regarding DHS data and ethical standards are available at: http://goo.gl/ny8T6X.

Map disclaimer The inclusion of any map (including the depiction of any boundaries therein), or of any geographic or locational reference, does not imply the expression of any opinion whatsoever on the part of BMJ concerning the legal status of any country, territory, jurisdiction or area or of its authorities. Any such expression remains solely that of the relevant source and is not endorsed by BMJ. Maps are provided without any warranty of any kind, either express or implied.

Competing interests None declared.

Patient and public involvement Patients and/or the public were not involved in the design, or conduct, or reporting, or dissemination plans of this research.

Patient consent for publication Not required.

Ethics approval We used datasets provided by the Demographic Health Surveys programme and have not had any form of contact with the study participants. The programme obtains approval from the Ethics Boards of the various partner organisations and countries such as the Ministries of Health. The DHS programme recognises and adheres to established international and local ethical standards and protocols in its surveys. The ICF International's Institutional Review Board (IRB) through The DHS programme's reviewed and approved all survey procedures and instruments used before implementation. The board aside from providing technical assistance to the programme ensures that the survey complies with the US Department of Health and Human Services regulations for the protection of human subjects CFR 46 as well as the laws of the individual countries. Further information regarding the DHS data usage and ethical standards can be accessed online (https://dhsprogramcom/data/Access-Instructionscfm).

Provenance and peer review Not commissioned; externally peer reviewed.

Data availability statement Data are available in a public, open access repository. Data for this study were sourced from Demographic and Health surveys (DHS) and available here: http://dhsprogram.com/data/available-datasets.cfm.

Open access This is an open access article distributed in accordance with the Creative Commons Attribution Non Commercial (CC BY-NC 4.0) license, which permits others to distribute, remix, adapt, build upon this work non-commercially, and license their derivative works on different terms, provided the original work is properly cited, appropriate credit is given, any changes made indicated, and the use is non-commercial. See: http://creativecommons.org/licenses/by-nc/4.0/.

\section{ORCID iDs}

Iddrisu Amadu http://orcid.org/0000-0003-4839-1197

Abdul-Aziz Seidu http://orcid.org/0000-0001-9734-9054

Bright Opoku Ahinkorah http://orcid.org/0000-0001-7415-895X

\section{REFERENCES}

1 Ntenda PAM, Nkoka O, Bass P, et al. Maternal anemia is a potential risk factor for anemia in children aged 6-59 months in Southern Africa: a multilevel analysis. BMC Public Health 2018;18:650.

2 Roberts DJ, Matthews G, Snow RW, et al. Investigating the spatial variation and risk factors of childhood anaemia in four sub-Saharan African countries. BMC Public Health 2020;20:126.

3 Organization WH, others. Haemoglobin concentrations for the diagnosis of anaemia and assessment of severity. vitamin and mineral nutrition information system. Geneva: World Heal Organ (WHO/ NMH/NHD/MNM/111), 2011. http//www who int/vmnis/indicators/ haemoglobin pdf

4 Nambiema A, Robert A, Yaya I. Prevalence and risk factors of anemia in children aged from 6 to 59 months in Togo: analysis from Togo demographic and health survey data, 2013-2014. BMC Public Health 2019;19:215.

5 Engelmann B, Massberg S, Wintrobe MM. Thrombosis as an intravascular effector of innate immunity. Nat Rev Immunol 2013:13:34-45

6 Soliman A, Abu-Hamila N, El-Ebiary M. Assessment of Biodentine as an indirect pulp capping material in young permanent molars. Indian J Endocrinol Metab 2019;16.

7 Wirth JP, Rohner F, Woodruff BA, et al. Anemia, Micronutrient Deficiencies, and Malaria in Children and Women in Sierra Leone Prior to the Ebola Outbreak - Findings of a Cross-Sectional Study. PLoS One 2016;11:e0155031.

8 Organization WH, others. Global nutrition targets 2025: anaemia policy brief. Geneva: World Health Organization, 2014.

9 Mishra V, Retherford RD. Does biofuel smoke contribute to anaemia and stunting in early childhood? Int J Epidemiol 2007;36:117-29.

10 van Gemert F, Chavannes N, Kirenga B, et al. Socio-Economic factors, gender and smoking as determinants of COPD in a lowincome country of sub-Saharan Africa: fresh air Uganda. NPJ Prim Care Respir Med 2016;26:1-6.

11 Machisa M, Wichmann J, Nyasulu PS. Biomass fuel use for household cooking in Swaziland: is there an association with anaemia and stunting in children aged 6-36 months? Trans $R$ Soc Trop Med Hyg 2013;107:535-44.

12 Woolley KE, Bagambe T, Singh A, et al. Investigating the association between wood and charcoal domestic cooking, respiratory symptoms and acute respiratory infections among children aged under 5 years in Uganda: a cross-sectional analysis of the 2016 demographic and health survey. Int J Environ Res Public Health 2020;17:3974.

13 Organization WH, others. WHO Air quality guidelines for particulate matter, ozone, nitrogen dioxide and sulfur dioxide: global update 2005: summary of risk assessment, 2006.

14 Accinelli RA, Leon-Abarca JA. Solid fuel use is associated with anemia in children. Environ Res 2017;158:431-5. 
15 Amegah AK, Boachie J, Näyhä S, et al. Association of biomass fuel use with reduced body weight of adult Ghanaian women. J Expo Sci Environ Epidemiol 2020;30:670-9.

16 Page CM, Patel A, Hibberd PL. Does smoke from biomass fuel contribute to anemia in pregnant women in Nagpur, India? A crosssectional study. PLoS One 2015;10:e0127890.

$17 \mathrm{Kyu} \mathrm{HH}$, Georgiades K, Boyle MH. Biofuel smoke and child anemia in 29 developing countries: a multilevel analysis. Ann Epidemiol 2010;20:811-7.

18 Desai MA, Mehta S, Smith KR, et al. Indoor smoke from solid fuels: assessing the environmental burden of disease at national and local levels. World Health Organization, 2004.

19 Begum BA, Paul SK, Dildar Hossain M, et al. Indoor air pollution from particulate matter emissions in different households in rural areas of Bangladesh. Build Environ 2009;44:898-903.

20 Chakraborty D, Mondal NK, Datta JK. Indoor pollution from solid biomass fuel and rural health damage: a micro-environmental study in rural area of Burdwan, West Bengal. Int J Sustain built Environ 2014;3:262-71.

21 Pinto VS. An analysis of association between using solid fuel and anemia among reproductive age women, 15-49 years old in TimorLeste, 2016.

22 Baranwal A, Baranwal A, Roy N. Association of household environment and prevalence of anemia among children under-5 in India. Front Public Health 2014;2:196.

23 Epstein MB, Bates MN, Arora NK, et al. Household fuels, low birth weight, and neonatal death in India: the separate impacts of biomass, kerosene, and coal. Int J Hyg Environ Health 2013;216:523-32.

24 Ali SA, Khan U, Feroz A. Prevalence and determinants of anemia among women of reproductive age in developing countries. $J$ Coll Physicians Surg Pak 2020;30:177-86.

25 Naz S, Page A, Agho KE. Household air pollution from use of cooking fuel and under-five mortality: the role of breastfeeding status and kitchen location in Pakistan. PLoS One 2017;12:e0173256.

26 Sreeramareddy CT, Shidhaye RR, Sathiakumar N. Association between biomass fuel use and maternal report of child size at birth-an analysis of 2005-06 India Demographic Health Survey data. BMC Public Health 2011;11:403.

27 Yaya S, Uthman OA, Ekholuenetale M, et al. Effects of birth spacing on adverse childhood health outcomes: evidence from 34 countries in sub-Saharan Africa. J Matern Fetal Neonatal Med 2020;33:3501-8.

28 Organization $\mathrm{WH}$, others. Progress on drinking water, sanitation and hygiene: 2017 update and SDG baselines, 2017

29 Armah FA, Ekumah B, Yawson DO, et al. Access to improved water and sanitation in sub-Saharan Africa in a quarter century. Heliyon 2018;4:e00931.

30 Chandran V, Kirby RS. An analysis of maternal, social and household factors associated with childhood anemia. Int J Environ Res Public Health 2021;18. doi:10.3390/ijerph18063105. [Epub ahead of print: 1703 2021].

31 Armah FA, Ekumah B, Yawson DO, et al. Predictive probabilities of access to clean cooking: evidence from the demographic and health surveys in 31 countries in sub-Saharan Africa. Environ Justice 2019;12:118-31.

32 Zhou N, Cui Z, Yang S, et al. Air pollution and decreased semen quality: a comparative study of Chongqing urban and rural areas. Environ Pollut 2014;187:145-52.

33 Hulin M, Caillaud D, Annesi-Maesano I. Indoor air pollution and childhood asthma: variations between urban and rural areas. Indoor Air 2010;20:502-14

34 UNICEF. Clear the air for children: the impact of air pollution on children, 2016. Available: https://www.unicef.org/media/60106/file\% $0 \mathrm{~A} \% 0 \mathrm{~A}$

35 Pathak U, Gupta NC, Suri JC. Risk of COPD due to indoor air pollution from biomass cooking fuel: a systematic review and metaanalysis. Int J Environ Health Res 2020;30:75-88.

36 Amadu I, Seidu A-A, Duku E, et al. The joint effect of maternal marital status and type of household cooking fuel on child nutritional status in sub-Saharan Africa: analysis of cross-sectional surveys on children from 31 countries. Nutrients 2021;13. doi:10.3390/nu13051541. [Epub ahead of print: 03 May 2021]
37 Mensah CA. Urban Green Spaces in Africa : Nature and Challenges 2014;4:1-11.

38 Ross CE, Mirowsky J. Neighborhood socioeconomic status and health: context or composition? City Community 2008;7:163-79.

39 Weiss G, Goodnough LT. Anemia of chronic disease. N Engl J Med 2005;352:1011-23.

40 Gebreegziabiher G, Etana B, Niggusie D. Determinants of anemia among children aged 6-59 months living in Kilte Awulaelo Woreda, Northern Ethiopia. Anemia 2014;2014:1-9.

41 Dos Santos RF, Gonzalez ESC, de Albuquerque EC, et al. Prevalence of anemia in under five-year-old children in a children's hospital in Recife, Brazil. Rev Bras Hematol Hemoter 2011;33:100-4.

42 Ali D, Saha KK, Nguyen PH, et al. Household food insecurity is associated with higher child undernutrition in Bangladesh, Ethiopia, and Vietnam, but the effect is not mediated by child dietary diversity. J Nutr 2013;143:2015-21.

43 Gebreweld A, Ali N, Ali R, et al. Prevalence of anemia and its associated factors among children under five years of age attending at Guguftu health center, South Wollo, northeast Ethiopia. PLoS One 2019;14:e0218961.

44 Asresie MB, Fekadu GA, Dagnew GW. Determinants of anemia among children aged 6-59 months in Ethiopia: further analysis of the 2016 Ethiopian demographic health survey. Adv Public Health 2020;2020:1-6.

45 Muniz PT, Castro TGde, Araújo TSde, et al. Child health and nutrition in the Western Brazilian Amazon: population-based surveys in two counties in ACRE state. Cad Saude Publica 2007;23:1283-93.

46 Prieto-Patron A, Van der Horst K, Hutton ZV, et al. Association between anaemia in children 6 to 23 months old and child, mother household and feeding indicators. Nutrients 2018;10:1269.

47 Zhao A, Zhang Y, Peng Y, et al. Prevalence of anemia and its risk factors among children 6-36 months old in Burma. Am J Trop Med Hyg 2012;87:306-11.

48 Pasricha S-R, Black J, Muthayya S, et al. Determinants of anemia among young children in rural India. Pediatrics 2010;126:e140-9.

49 Agbozo F, Colecraft E, Jahn A, et al. Understanding why child welfare clinic attendance and growth of children in the nutrition surveillance programme is below target: lessons learnt from a mixed methods study in Ghana. BMC Nurs 2018;17:25.

50 Abdi Guled R, Mamat NM, Balachew T. Predictors and prevalence of anemia, among children aged 6 to 59 months in shebelle zone, Somali region, eastern Ethiopia: a cross sectional study. Int J Dev Res 2017;7:11189-96.

51 Khan JR, Awan N, Misu F. Determinants of anemia among 6-59 months aged children in Bangladesh: evidence from nationally representative data. BMC Pediatr 2016;16:3.

52 Parbey P, Kyei-Duodu G, Takramah W, et al. Prevalence of anaemia and associated risk factors among children under five years in hohoe municipality, Ghana. J Sci Res Rep 2017;15:1-12.

53 Kuziga F, Adoke Y, Wanyenze RK. Prevalence and factors associated with anaemia among children aged 6 to 59 months in Namutumba district, Uganda: a cross- sectional study. BMC Pediatr 2017;17:25.

54 De Pee S, Bloem MW, Sari M, et al. The high prevalence of low hemoglobin concentration among Indonesian infants aged 3-5 months is related to maternal anemia. J Nutr 2002;132:2215-21.

55 Engidaye G, Melku M, Yalew A, et al. Under nutrition, maternal anemia and household food insecurity are risk factors of anemia among preschool aged children in Menz Gera Midir district, eastern Amhara, Ethiopia: a community based cross-sectional study. BMC Public Health 2019;19:968.

56 Khan JR, Awan N. A comprehensive analysis on child mortality and its determinants in Bangladesh using frailty models. Arch Public Health 2017;75:1-10.

57 Ngnie-Teta I, Receveur O, Kuate-Defo B. Risk factors for moderate to severe anemia among children in Benin and Mali: insights from a multilevel analysis. Food Nutr Bull 2007;28:76-89.

58 Kothari MT, Coile A, Huestis A, et al. Exploring associations between water, sanitation, and anemia through 47 nationally representative demographic and health surveys. Ann N Y Acad Sci 2019;1450:249.

59 Magadi M, Desta M. A multilevel analysis of the determinants and cross-national variations of HIV seropositivity in sub-Saharan Africa: evidence from the DHS. Health Place 2011;17:1067-83. 